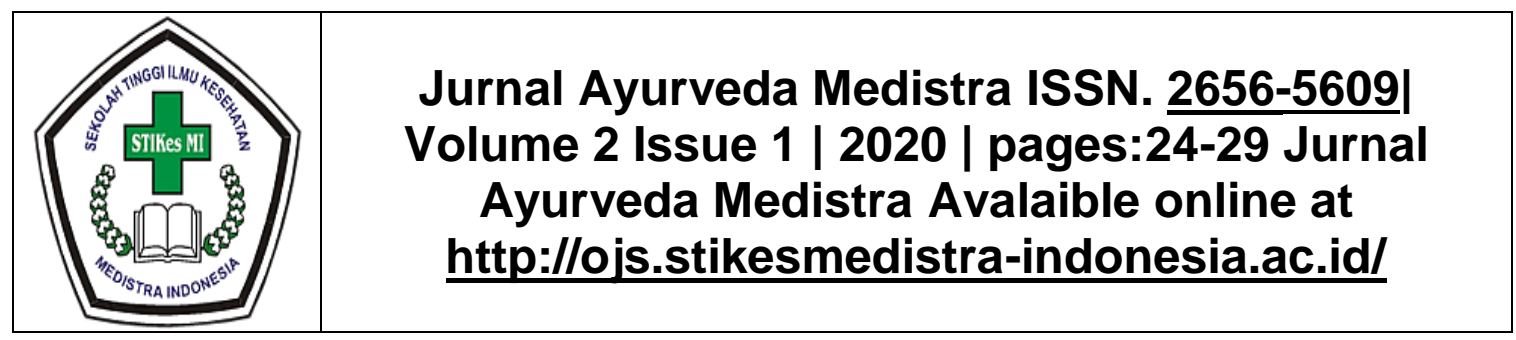

\title{
HUBUNGAN HIPERTENSI DALAM KEHAMILAN DENGAN KEJADIAN BERAT BAYI LAHIR RENDAH DI RS GRAHA JUANDA TAHUN 2018
}

\author{
Riyen Sari Manulang ${ }^{1}$, Farida Simanjuntak \\ ${ }^{1}$ Program Studi Kebidanan (D3) STIKes Medistra Indonesia, riyen88@gmail.com, 08170050977 \\ 2 Program Studi Kebidanan (S1) STIKes Medistra Indonesia, faridams@gmail.com, 082261068881
}

\begin{abstract}
ABSTRAK
Latar Belakang : Kematian ibu di Indonesia masih didominasi oleh tiga penyebab utama kematian yaitu perdarahan, hipertensi dalam kehamilan (HDK), dan infeksi. Namun proporsinya telah berubah, dimana perdarahan dan infeksi cenderung mengalami penurunan sedangkan proporsi hipertensi dalam kehamilan (HDK) semakin meningkat menjadi penyebab utama. Lebih dari 25\% kematian ibu di Indonesia pada tahun 2013 disebabkan oleh HDK. Tujuan Penelitian : Untuk mengetahui hubungan hipertensi dalam kehamilan dengan kejadian berat badan lahir rendah di RS Graha Juanda tahun 2018 Metode Penelitian : Penelitian ini bersifat analitik dengan desain studi restrosfektif. Populasi dalam penelitian ini adalah rekam medis ibu bersalin dengan yang mengalami Hipertensi dalam kehamilan di RS. Graha Juanda tahun 2018 yang berjumlah 850 orang. Sampel dalam penelitian ini jenis total sampling, yaitu dengan mengambil semua populasi ibu bersalin yang mengalami hipertensi dalam kehamilan (HDK). Analisis statistik yang digunakan adalah Chi-Square. Hasil Penelitian : Analisis Chi-Squere menunjukan nilai uji statistik dengan menggunakan uji t di dapatkan hasil pvalue 0,001 maka terdapat pengaruh yang signifikan hipertensi dalam kehamilan dengan kejadian berat bayi lahir rendah.

Kesimpulan : Terdapat hubungan hipertensi dalam kehamilan dengan kejadian berat badan lahir rendah di RS Graha Juanda tahun 2018.
\end{abstract}

Kata Kunci : HDK, BBLR, Ibu Hamil

\begin{abstract}
Background: maternal deaths in Indonesia still consider three main causes of death, namely bleeding, hypertension in pregnancy, and infection. However, the proportions have changed, where increased bleeding and infections ultimately lead to hypertension in pregnancy which is increasingly the main cause. More than $25 \%$ of maternal deaths in Indonesia in 2013 were caused by hypertension in pregnancy..Research purposes: to determine the relationship of hypertension in pregnancy with the incidence of low birth weight in Graha Juanda Hospital year 2018.Research method: : Design research analytic with retrospective study design. Population in this study study is the medical record of women with maternal hypertension of pregnancy at the Hospital Graha Juanda in 2018, amounting to 850 people. The sample $\mathrm{n}$ this study was a total sampling type, namely by taking all the population of maternity women who experience hypertension in pregnancy. The statistical analysis used is ChiSqure.Research result: Analysis Chi- Squere shows value test statistics with use test at get it results pvalue 0.001 then there is a significant hypertension in pregnancy with incidence of low birth weight babies. Conclusion : From the results analysis there is relationship of hypertension in pregnancy with the incidence of low birth weight in Graha Juanda Hospital in 2018.
\end{abstract}

Keywords: hypertension in pregnancy, low birth weight of babies, pregnancy 
830 wanita meninggal setiap hari karena komplikasi selama kehamilan atau persalinan pada tahun 2015. Mengurangi rasio kematian ibu secara global dari 216 per 100.000 kelahiran hidup pada tahun 2015 menjadi kurang 70 per 100.000 kelahiran hidup pada tahun 2030 akan membutuhkan tingkat pengurangan tahunan global minimal $7,5 \%$ yang merupakan lebih dari tiga kali lipat tingkat pengurangan tahunan yang dicapai antara tahun 1990 dan 2015. Pada 2016, jutaan kelahiran secara global tidak dibantu oleh bidan terlatih, dokter atau perawat, dengan hanya $78 \%$ kelahiran berada di hadapan seorang petugas kelahiran terampil (WHO, 2017). ${ }^{1}$ Badan Kesehatan Dunia (WHO, 2013) menyebutkan angka kejaadian hipertensi terus meningkat secara global dan diprediksi pada tahun 2025 sekitar $29 \%$ orang dewasa di seluruh dunia akan mengalami hipertensi, ini menjadi sebuah tantangan besar bagi dunia. ${ }^{2}$

Angka kejadian Hipertensi Dalam Kehamilan (HDK) sebesar 5-15\% dari seluruh kehamilan di dunia, angka kejadian ini lebih banyak terjadi di Negara berkembang disbanding pada Negara maju. Mencatat angka kematian ibu akibat HDK sebesar 31,57 \%. Di Inggris kurang dari 10 wanita meninggal tiap tahun, dan di negara berkembang 50.000 kematian maternal disebabkan oleh $\mathrm{HDK}^{4}$ Hasil Survei Demografi Kesehatan Indonesia (SDKI) tahun 2012, Angka Kematian Ibu (AKI) di Indonesia mencapai 359 per 100.000 kelahiran hidup dan Angka Kematian Bayi (AKB) mencapai 32 per 1000 kelahiran hidup. Adapun faktor penyebab langsung kematian ibu adalah perdarahan $40-60 \%$, infeksi 20 $30 \%$, Hipertensi dalam kehamilan $32 \%$, APB $3 \%$, Abortus $4 \%$, partus lama $1 \%$, komplikasi puerperium $31 \%$, kelainan amnion $2 \%$, lainnya (7\%) seperti gemeli (kehamilan ganda), ketuban pecah dini dan lain-lain. ${ }^{5}$

Hipertensi masih merupakan tantangan besar di Indonesia. Betapa tidak, hipertensi merupakan kondisi yang sering ditemukan pada pelayanan kesehatan primer. Hal itu merupakan masalah kesehatan dengan prevelensi yang tinggi, yaitu sebesar $25,8 \%$, sesuai dengan data riskesdas 2013. Kematian ibu di Indonesia masih didominasi oleh tiga penyebab utama kematian yaitu perdarahan, hipertensi dalam kehamilan (HDK), dan infeksi. Namun proporsinya telah berubah, dimana perdarahan dan infeksi cenderung mengalami penurunan sedangkan proporsi hipertensi dalam kehamilan (HDK) semakin meningkat menjadi penyebab utama. Lebih dari $25 \%$ kematian ibu di Indonesia pada tahun 2013 disebabkan oleh HDK. ${ }^{3}$

Jumlah bayi baru lahir rendah (BBLR) di Indonesia masih cukup tinggi, Data WHO mencatat Indonesia berada di peringkat sembilan dunia dengan persentase lebih dari $15,5 \%$ dari kelahiran bayi setiap tahunnya. Wanita dengan HDK berisiko untuk melahirkan bayi dengan berat badan lahir rendah (BBLR). Pada hipertensi berat, perfusi uteroplasenta berkurang sehingga menyebabkan peningkatan insiden Intra Uterine Growth Retardition (IUGR) (Wadhwa dkk., 2004), hipoksia janin dan kematian perinatal. Oleh karena itu, pengenalan awal faktor risiko hipertensi dalam kehamilan sangat penting untuk menghindari dampak buruk pada ibu dan janin $^{6}$

Kematian ibu di Indonesia masih didominasi oleh tiga penyebab utama kematian yaitu perdarahan, hipertensi dalam kehamilan (HDK), dan infeksi. Namun proporsinya telah berubah, dimana perdarahan dan infeksi cenderung mengalami penurunan sedangkan proporsi hipertensi dalam kehamilan (HDK) semakin meningkat menjadi penyebab utama. Lebih dari $25 \%$ kematian ibu di Indonesia pada tahun 2013 disebabkan oleh HDK (Depkes RI, 2016). Ibu yang mengalami hipertensi dalam kehamilan (HDK) berkisar 10\%, 3-4 \% diantaranya mengalami preeklampsia, 5\% mengalami hipertensi gestasional dan 1-2\% mengalami hipertensi kronik. Berdasarkan data demikian, maka dapat disimpulkan bahwa hipertensi dalam kehamilan menjadi salah satu penyebab kematian ibu. Pre-eklampsia dan eklampsia adalah penyakit hipertensi yang terjadi pada kehamilan yang ditandai dengan hipertensi, edema, dan proteinuria setelah minggu ke-20, dan jika disertai kejang disebut eklampsia (Depkes RI, 2016). Penyebab terjadinya pre- eklampsia pada kehamilan belum dapat diketahui secara pasti, beberapa faktor resiko pre-eklampsia diantaranya kehamilan ganda, molahidatidosa, umur, obesitas, paritas ibu dan primigravida muda umur $<20$ tahun dan pada primigravida tua $>35$ tahun (Dewi, 2017).. 
BBLR (kurang dari 2.500 gram) merupakan salah satu faktor utama yang berkontribusi terhadap kematian perinatal dan neonatal. Berat bayi lahir rendah (BBLR) dibedakan dalan dua kategori yaitu BBLR karena premature (usia kandungan < 37 minggu) atau BBLR karena Intra Uterine Growth Retardation (IUGR) yaitu bayi cukup bulan tetapi berat kurang untuk usianya. Pada pasien HDK didapatkan resiko persalinan premature 2,67 kali lebih besar, dan persalinan buatan 4,39 kali lebih banyak dan mempunyai kecenderungan lebih tinggi untuk mendapatkan bayi dengan berat badan lahir rendah. ${ }^{9}$

Bayi dengan berat badan lahir rendah dari 2500 gram sampai saat ini masih merupakan penyebab utama morbiditas dan mortalitas perinatal serta neonatal. Berat Bayi Lahir Rendah (BBLR) dapat dibedakan atas bayi yang dilahirkan preterm dan bayi yang mengalami pertumbuhan intrauterin terhambat

Saat penulis melakukan pengamatan awal (Studi pendahuluan) di RS. Graha Juanda Peneliti medapatkan data bahwa pada tahun 2017 sebanyak 192 ibu yang mengalami Hipertensi Dalam Kehamilan (HDK) dan pada tahun 2018 ini terhitung mulai dari bulan Januari sampai dengan bulan Desember ini ada 272 ibu yang mengalami Hipertensi Dalam Kehamilan. Dan didapatkan kasus Berat Bayi Lahir Rendah (BBLR) pada tahun 2017 sebanyak 268 diantarannya 159 yang mengalami BBLR dan 109 yang tidak mengalami BBLR. Pada 3 bulan terakhir kasus BBLR sebanyak 125 kasus di tahun 2019. Berdasarkan uraian latar belakang diatas penulis tertarik untuk melakukan penelitian tentang Hubungan Hipertensi Dalam Kehamilan Dengan Kejaadian Berat Bayi Lahir Rendah Di RS. Graha Juanda Kota Bekasi 2018

\section{METODE PENELITIAN}

Penelitian ini dilakukan di RS Graha Juanda pada tahun 2019. Jenis penelitian yang digunakan adalah metode studi analitik bersifat kuantitatif. Jenis penelitian ini adalah studi retrospektif. Populasi dalam penelitian ini adalah rekam medis ibu bersalin di RS Graha Juanda tahun 2018 yang berjumlah 850 orang. Sampel dalam penelitian ini jenis total sampling,yaitu dengan mengambil semua populasi ibu bersalin yang mengalami hipertensi dalam kehamilan (HDK)

Adapun cara pengambilan data pada penelitian ini yaitu dengan Data yang dikumpulkan adalah data sekunder yang di dapat dari data rekam medik ibu bersalin yang mengalami kejadian hipertensi dalam kehamilan tahun 2018. Analisis data menggunakan program SPSS 20 for windows, analisis univariat digunakan untuk mendeskripsikan distribusi frekuensi variable hipertensi dalam kehamilan dengan baerat bayi lahir rendah, analisis bivariat untuk melihat

\section{HASIL}

Tabel 1. Disrtibusi frekuensi Hipertensi Dalam Kehamilan di RS Graha Juanda Bekasi Tahun 2018

\begin{tabular}{cccc}
\hline NO & Kategori & Frekuensi & Presentase \\
1. & HDK & 337 & 39.6 \\
2. & Tidak HDK & 513 & 60.4
\end{tabular}

Sumber: Rekam Medik 2019

Berdasarkan tabel 1 diperoleh hasil penelitian, bahwa distribusi frekuensi Hipertensi dalam Kehamilan di RS Graha Juanda Tahun 2018 tepatnya di Ruang Kebidanan berjumlah 850 responden, yang diantaranya terdiri dari 337 responden $(39,6 \%)$ yang mengalami Hipertensi Dalam Kehamilan dan sebanyak 513 responden $(60,4 \%)$ yang tidak mengalami HDK.

Tabel 2 Distribusi Frekuensi Kejadian BBLR di RS Graha Juanda Bekasi Tahun 2018

\begin{tabular}{cccc}
\multicolumn{2}{c}{2018} & & \\
\hline NO & Kategori & Frekuensi & Presentase \\
\hline 1 & BBLR & 269 & 31.6 \\
2 & Tidak BBLR & 581 & 68.4 \\
\hline & Jumlah & 850 & 100.0 \\
\hline
\end{tabular}

Sumber: Rekam Medik 2019

Berdasarkan tabel 4.2 diperoleh hasil penelitian tentang Distribusi frekuensi kejadian Berat Bayi Lahir Rendah di RS Graha Juanda Bekasi Tahun 2018 tepatnya di Ruang Kebidanan sebanyak $269(31,6)$ kejadian BBLR, dan sebanyak $581(68,4 \%)$ yang tidak BBLR. 
Tabel 3. Hubungan Hipertensi Dalam Kehamilan dengan Kejadian Berat Bayi Lahir Rendah

\begin{tabular}{|c|c|c|c|c|c|c|c|c|}
\hline \multirow[t]{3}{*}{$\mathrm{NO}$} & \multirow[t]{3}{*}{ Diagnosa } & \multicolumn{4}{|c|}{ Kejadian } & \multirow[t]{3}{*}{ Total } & \multirow[t]{3}{*}{$\%$} & \multirow[t]{3}{*}{$P$ value } \\
\hline & & \multicolumn{2}{|c|}{ BBLR } & \multicolumn{2}{|c|}{$\begin{array}{l}\text { Tidak } \\
\text { BBLR } \\
\end{array}$} & & & \\
\hline & & $\mathrm{F}$ & $\%$ & $F$ & $\%$ & & & \\
\hline 1 & HDK & 189 & 56,1 & 148 & 43,9 & 337 & 100.0 & 0.001 \\
\hline \multirow[t]{2}{*}{2} & Tidak HDK & 80 & 15,6 & 433 & 84,4 & 513 & 100.0 & \\
\hline & Total & 269 & 70,2 & 581 & 68,4 & 850 & 100.0 & \\
\hline
\end{tabular}

Sumber: Rekam Medik 2019

\section{PEMBAHASAN}

Hasil penelitian ini didapatkan dari 850 responden, yang mengalami Hipertensi dalam kehamilan (HDK) dan Berat Bayi Lahir Rendah sebanyak 189 responden $(56,1 \%)$ dan responden yang mengalami HDK tetapi tidak BBLR sebanyak 148 responden (43,9\%). Responden yang mengalami Tidak HDK dan bayi dengan berat lahir rendah sebanyak 80 responden (15,6\%) dan responden yang Tidak HDK dan BBLR sebanyak 433 responden $(84,4 \%)$. Hasil uji statistik dengan chi square didapatkan nilai $p=0,001 \quad(p<0,05)$. Hal ini menunjukan bahwa $\mathrm{H} 0$ ditolak dan $\mathrm{Ha}$ diterima, maka dapat disimpulkan ada hubungan hipertensi dalam kehamilan dengan kejadian berat bayi lahir rendah di RS Graha Juanda Bekasi Tahun 2018.

Hasil tersebut dapat dijelaskan karena saat ibu hamil mengalami hipertensi, maka asupan makanan terhadap janin menjadi terhambat karena adanya penyempitan pembuluh darah. Asupan makanan yang terhambat menyebabkan perkembangan janin dalam kandungan menjadi terhambat. Pada akhirnya bayi terlahir dengan berat lahir rendah ( Proverawati, 2015)

Asupan makanan yang terhambat juga dipengaruhi oleh pola diet yang dilakukan oleh ibu hamil Hipertensi. Jumlah konsumsi makanan yang berkurang pada ibu hamil juga akan menyebabkan asupan nutrisi pada janin juga berkurang. Hal ini berdampak pada perkembangan janin menjadi kurang optimal dan meningkatkan risiko bayi lahir dengan berat badan rendah.

Hipertensi dalam kehamilan akan mengalami perubahan fisiologis patologis diantaranya perubahan pada plasenta dan uterus yang disebabkan oleh menurunnya aliran darah ke plasenta. Hal ini dapat menyebabkan terjadinya gangguan pada fungsi plasenta. Pada waktu yang lama, akan menyebabkan pertumbuhan janin menjadi terganggu. Hipertensi dalam kehamilan mempengaruhi terjadinya BBLR karena Hipertensi dapat menyebabkan persalinan prematur. Bayi yang lahir sebelum waktunya maka perkembangannya belum sempurna. Bayi yang lahir prematur dapat dipastikan lahir dengan berat lahir yang rendah.

Berdasarkan hasil penelitian ini diketahui sebagian besar responden mengalami hipertensi dan melahirkan bayi dengan berat lahir rendah. Pada ibu hamil yang tidak HDK juga demikian, sebagian besar melahirkan bayi dengan berat lahir yang rendah. Hasil ini menunjukkan bahwa hipertensi pada ibu hamil merupakan faktor yang menyebabkan berat badan bayi lahir rendah. Suhardjo (2016) menyebutkan berat badan lahir dapat ditimbulkan oleh dua sebab yaitu prematur (lahir sebelum waktunya) dan karena perkembangan janin yang terlambat. Kelahiran prematur dapat diakibatkan oleh faktor ibu yaitu mengalami tekanan darah tinggi atau infeksi akut 


\section{KESIMPULAN}

Berdasarkan penelitian terhadap 850 responden yang dilakukan di RS Graha Juanda Bekasi Tahun 2018, maka beberapa kesimpulan yang dapat dijelaskanpada penelitian ini adalah sebagai berikut : Diketahui jumlah kasus hipertensi dalam kehamilan (HDK) sebanyak 337 responden $(39,6 \%)$ dan yang Tidak HDK sebanyak 513 responden $(60,4 \%)$. Diketahui jumlah kejadian berat bayi lahir rendah (BBLR) sebanyak 269 responden $(31,6 \%)$ dan tidak BBLR sebanyak

581 responden $(68,4 \%)$. Ada hubungan hipertensi dalam kehamilan dengan kejadian bayi baru lahir rendah didapatkan nilai $p=0,001$ $(p<0,05)$.

\section{SARAN}

Bagi peneliti selanjutnya diharapkan membandingkan juga angka kejadian tersebut sehingga dapat terlihat perbandingan ibu hamil dengan hipertensi yang melahirkan BBLR dengan yang melahirkan bayi normal. Bagi Penyedia Layanan Kesehatan dan Pemeriksaan Kehamilan terutama Bidan yang lebih dekat dengan masyarakat terutama penyedia antenatal care atau pemeriksaan kehamilan diharapkan dapat meningkatkan sosialisasi tentang hal-hal yang berkaitan dengan topik kehamilan baik fisiologi maupun kehamilan berisiko tinggi, masalah kegawatdaruratan ibu dan bayi baru lahir sehingga ibu hamil mendapat informasi yang cukup seputar kehamilannya, terutama ibu hamil dengan kebutuhan khusus seperti hipertensi agar hipertensi yang dialami ibu hamil tidak semakin memburuk dan janin mendapat nutrisi yang cukup sehingga lahir dengan berat normal.

\section{DAFTAR PUSTAKA}

1. Depkes RI. (2016). Jurnal Kebidanan. $X(2), 127-134$.

2. Ika. (2015). Jumlah Bayi Berat Lahir Rendah Masih Tinggi. Universitas Gadjah Mada, (November), 2015-2017.

3. NHBPEP. (2013). National High Blood Pleasure Education Program, 52(1), 15.

4. Notoatmodjo, S. (2012). METODOLOGI PENELITIAN
KESEHATAN (Edisi revi; S. Notoatmodjo, ed.). Jakarta: Rineka Cipta.

5. Khairina. (2015) 'Faktor yang Berhubungan dengan Kejadian bayi baru lahir rendah di Rumah Sakit Bantuan Lawang', Jurnal Hesti Wira Sakti, 4(1), pp. 101-109.

6. Julia, L., Jaelani, R. and Venny, S. (2015) 'Hubungan HDK Dengan Angka Kejadian BBLR Di Wilayah Kerja RS Indrasari Rengat ', 8(1), pp. 33-44.

7. Hastono, S. P. (2016) Analisis Data Pada Bidang Kesehatan. 1st edn. Jakarta: PT RajaGrafindo Persada.

8. Proverawati $A$ and Ismawati, C. (2016) Bayi Baru Lahir Rendah. Yogyakarta: Nuha Medika.

9. Murtala, I. (2016) 'Gambaran Tekanan Darah Ibu Hamil Dan Berat Badan Lahir Rendah Pada lbu yang Melahirkan De', IMJ: Indonesian Midwifery Journal, 1(1), pp. 24-34.

10. Karlina, N., Ermalinda, E. and Pratiwi, W. M. (2016) Asuhan Kebidanan Kegawatdaruratan Maternal dan Neonatal. Pertama. Bogor: IN MEDIA.

11. NICE. (2016) 'Hipertensi Dalam Kehamilan, Vol. 7 No. 1 Juli 2016 Khadijah, et. al.', 7(1). Available at: https://docobook.com/dinamikakesehatan-vol-7-no-1-juli-2016- faktorfaktoradac420f926d17e81857ee29177 04a2f17810.html. diakses pada

12. Junaidi, R. (2016) Hubungan Faktor usia dengan kejadian hipertensi pada ibu hamil. Indonesian Midwifery Journal, 1(1), pp. 24-34.

13. Astuti, A. and Sari, E. P. (2013) Asuhan Kegawatdaruratan Maternal \& Neonatal. Kedua. Edited by T. Ismail. Jakarta: Trans Info Media.

14. Notoatmodjo, S. (2012) METODOLOGI PENELITIAN KESEHATAN. Edisi revi. Edited by S. Notoatmodjo. Jakarta: Rineka Cipta.

15. Purwoastuti, T. E. and Walyani, E. S. 
(2015a) Panduan Materi Kesehatan Reproduksi dan Keluarga Berencana. Pertama. Yogyakarta: PUSTAKA BARU PRESS.

16. Zuraidah, N. Utami and Jualiandi (2014) 'FAKTOR RISIKO BERAT BADAN LAHIR RENDAH DI RSU MADANI MEDAN.', VII(2), pp. 43-

49. diakses pada

17. Saifuddin, A. B., Rachimhadhi, T. and Wiknjosastro, G. H. (2014) ILMU KEBIDANAN SARWONO PRAWIROHARDJO. Keempat. Edited by T. Rachimhadhi and G. H. Wiknjosastro. Jakarta: PT Bina Pustaka Sarwono Prawirohardjo.

18. Sari, A., Ulfa, I. M. and Daulay, R. (2016) Asuhan Kebidanan Kehamilan.

I. Bogor: IN MEDIA.

19. Dewi. (2017) 'Determinan Hipertensi Dalam Kehamilan (Analisis Lanjut Data Riskesdas 2013)', Jurnal Kesehatan Reproduksi, 8(1), pp. 63-

75. doi: 10.22435/kespro.v8i1.6641.63-75. diakses pada

20. WHO (2017) STATUS OF THE HEALTHRELATED SDGs. Available at: http://www.who.int/gho/publications/ world_health_statistics/2017/EN_WH S2017_Part2.pdf. diakses pada

21. World Health Organization Human Reproduction Programme, 10 April 2015 (2015) 'WHO Statement on caesarean section rates.', Reproductive health matters, 23(45), pp. 149-50. doi: 10.1016/j.rhm.2015.07.007. diakses pada

22. Suhardjo, M. (2016) 'Analisa Indikasi Hipertensi Pada ibi Hamil Di RSUP Dr. Soeradji Tirtonegoro Klaten', skripsi. Universitas Muhammadiyah Surakarta. diakses pada 